\title{
Gestão da inovação de produto: proposição de um modelo integrado
}

\author{
Juliano Pavanelli Stefanovitza, Marcelo Seido Nagano ${ }^{\mathrm{b*}}$ \\ ajulianops@yahoo.com, USP, Brasil \\ b*drnagano@usp.br, USP, Brasil
}

\begin{abstract}
Resumo
Este trabalho tem por objetivo estabelecer um panorama teórico da gestão do processo de inovação de produto e de seus desafios. Apesar de a importância da inovação ser amplamente reconhecida, há consenso de que as práticas de gestão que a potencializam permanecem ainda não totalmente desvendadas. Vários autores já comprovaram a complexidade do processo de inovação ao mostrar que ele envolve uma intrincada composição de risco e incerteza, necessidade de intensa orquestração multifuncional e a busca permanente de sintonia entre criação e disciplina. Reconhece-se, também, que, apesar dos avanços na última década, a literatura ainda carece de pesquisas que agreguem contribuições de diversas áreas em modelos integrados para gestão sistêmica da inovação. Baseado em revisão bibliográfica da literatura atual, é proposto um modelo composto por três dimensões (processos, contexto organizacional e recursos) e os desafios da inovação são investigados sob a óptica dessa estruturação teórica. Além da síntese conceitual sugerida, o presente artigo estabelece um referencial teórico que pode ser útil para pesquisas futuras ligadas ao tema.
\end{abstract}

Palavras-chave

Inovação. Gestão. Produto. Processo. Organização. Modelo.

\section{Introdução}

É amplamente reconhecida a crescente importância da inovação para a competitividade. Esse reconhecimento ocorre de forma intensa tanto no meio acadêmico quanto no meio empresarial. Vários autores já reforçaram a necessidade de as organizações inovarem para obter sucesso sustentável nos mercados em que atuam ou mesmo para reinventar tais mercados.

A despeito da reconhecida relevância da inovação, os processos de gestão que contribuem para a sua performance e os fatores que a inibem permanecem ainda não totalmente explicados. A literatura voltada para o tema esteve, por muito tempo, fragmentada, com pesquisas conduzidas em diferentes áreas com relativamente pouca interação (TIDD; BESSANT; PAVITT, 2008). Na última década, vêm sendo propostas abordagens mais sistêmicas para o entendimento e o gerenciamento do processo inovador. Entretanto, há latente necessidade de pesquisas que aprofundem temas como estratégia, governança dos processos, gestão de pessoas e inovação aberta, dentre outros, sob a óptica dos desafios que as organizações enfrentam para inovar (DI BENEDETT0, 2012).

Nesse contexto, o presente artigo tem como objetivo, além de sintetizar contribuições de diversas áreas num modelo integrado para a gestão da inovação, apresentar uma estrutura conceitual para o entendimento dos desafios da gestão da inovação. Dessa forma, consolida um referencial teórico abrangente que pode ser útil às pesquisas futuras e propõe direções para o avanço das teorias voltadas para o aumento da performance inovativa. Assim, esta pesquisa pode ser tipificada como teórica, de natureza exploratória e com método bibliográfico.

Após esta primeira seção introdutória, é apresentada a seção em que, baseado em extensa pesquisa bibliográfica, é proposta a construção de um modelo integrado para a gestão da inovação. A terceira seção, após consolidar contribuições sobre os desafios que as empresas encontram para inovar, 
propõe síntese conceitual da relação entre esses desafios e os elementos apresentados no modelo integrado de gestão da inovação. Por fim, uma seção de considerações finais consolida as principais conclusões e contribuições do trabalho.

\subsection{A inovação e a gestão da inovação: conceituação}

Uma importante referência atual para a definição de inovação pode ser encontrada no Manual de Oslo. Esse documento, publicado pela OCDE (Organização para a Cooperação e Desenvolvimento Econômico), tem por objetivo orientar e padronizar conceitos, metodologias e a construção de indicadores de pesquisa de inovação na indústria. Em sua terceira edição, adota a seguinte definição para a inovação:

A implementação de um produto (bem ou serviço) novo ou significativamente melhorado, ou um processo, ou um novo método de marketing, ou um novo método organizacional nas práticas de negócios, na organização do local de trabalho ou nas relações externas. (ORGANIZAÇÃO..., 2006).

Sabe-se que, para se obter sucesso por meio da inovação, uma complexa gama de atividades deve acontecer de forma coordenada e sincronizada. Esse entendimento de que a inovação não é um simples evento, mas sim um processo, exige que ela seja gerenciada como tal. Analisando sob essa óptica, Tidd, Bessant e Pavitt (2008) defendem que o processo de gestão da inovação envolve: a busca de uma abordagem estratégica para a inovação e para o desafio de sua gestão; o desenvolvimento de mecanismos e estruturas de implementação efetivos; o desenvolvimento de um contexto organizacional que suporte a inovação e a construção de interfaces externas efetivas.

Fica evidente que o processo está relacionado à ação gerencial: ações direcionadas por estratégias claras, objetivos e visão, ação disciplinada pela coleta sistemática de informações e ação que eventualmente renova a organização pela mudança. Assim, apesar dos obstáculos técnicos inerentes ao processo de inovação, constata-se que boa parte dos insucessos se deve a fraquezas no modo como ele é gerenciado (TIDD; BESSANT; PAVITT, 2008).

\section{Modelo integrado para a gestão da inovação}

Como ponto de partida para a construção de um referencial teórico, propõe-se a organização dos elementos da gestão da inovação organizada em três dimensões fundamentais: processos, contexto organizacional e recursos. A construção desse modelo se deu pela síntese de obras oriundas de diferentes áreas e tem como bases estruturais os modelos de Tidd, Bessant e Pavitt (2008) e Quadros (2008).

\subsection{Processos de gestão da inovação}

As abordagens modernas para a inovação reconhecem que ela não deve ser enxergada como um evento isolado, mas como um processo. Esse caráter processual explicita a necessidade de se concatenar de forma estruturada as várias atividades e áreas envolvidas nesse desafio. Além disso, reforça a importância de se mapear as relações entre as áreas e de se desenvolver um conjunto de práticas e rotinas que potencializem e acelerem a execução da atividade inovadora (TIDD; BESSANT; PAVITT, 2008). A seguir é caracterizado cada um dos processos de gestão da inovação.

\subsubsection{Prospecção}

Ao se introduzir um produto inovador no mercado, uma nova proposta de valor ao cliente/consumidor será entregue. Dessa forma, são partes fundamentais do processo inovador a coleta e a análise de informações sobre a existência de oportunidade de se colocar um elemento novo na arena competitiva. Denomina-se prospecção esse exercício de captação e entendimento das tendências de mudança do estado presente.

Quando se aborda a inovação de produto, a possibilidade de introduzirem-se inovações pode partir de diversas dimensões: (1) advento de novas tecnologias capazes de oferecer novas soluções e benefícios; (2) mudanças no macroambiente capazes de influenciar realidades setoriais específicas; (3) novas tendências de consumo e necessidades por parte de consumidores/clientes; e (4) movimentos da concorrência que alimentem novas estratégias de mercado. Na Tabela 1 são apresentados os principais elementos dessas dimensões.

\subsubsection{Ideação}

Boas ideias são a matéria-prima da inovação. 0 ineditismo necessário para haver inovação exige que, em algum momento, haja uma proposta diferente para resolver um problema ou aproveitar uma oportunidade. Na ideação se busca, pelos sinais coletados na análise prospectiva, a proposição de insights e pré-projetos em linha com as oportunidades identificadas.

Essa fase é responsável por gerar propostas que rompam a fronteira entre o existente e o desejável. É momento de criação, mas não é composto apenas de 
Tabela 1. Dimensões e ferramentas do processo prospectivo.

\begin{tabular}{llll}
\multicolumn{1}{c}{ Dimensão } & \multicolumn{1}{c}{ Foco } & \multicolumn{1}{c}{ Ferramentas } & Referências \\
\hline Macroambiente & $\begin{array}{l}\text { Mapear tendências do ambiente geral } \\
\text { que influenciam o futuro do setor }\end{array}$ & $\begin{array}{l}\text { Construção de cenários; método Delphi } \\
\text { Consuisa etnográfica; focus group e }\end{array}$ & Siems (2008); Shell (2002) \\
Consumidor & $\begin{array}{l}\text { Capturar tendências de benefícios a } \\
\text { serem entregues por inovações }\end{array}$ & $\begin{array}{l}\text { Pesqainstorming com consumidores; análise } \\
\text { de lead users }\end{array}$ & Cooper (2009); Von Hippel (2005) \\
Tecnologia & $\begin{array}{l}\text { Capturar tendências de novas soluções } \\
\text { para atender necessidades atuais e }\end{array}$ & $\begin{array}{l}\text { Mapeamento de patentes; método } \\
\text { Delphi; previsão por extrapolação; TRlZ }\end{array}$ & Slocum e Lundberg (2003) \\
\hline
\end{tabular}

inspiração. Trata-se de um trabalho intenso de análise de informações, cruzamento de sinais e tendências de diferentes áreas do conhecimento, junção de fragmentos, geração e avaliação de ideias.

Apesar da dificuldade de se estruturar com precisão o trabalho de criação, ele pode ser minimamente disciplinado. Dentre as boas práticas desse desafio, destacam-se a captura de ideias já existentes; a manutenção de ideias vivas e a indução de suas evoluções; a imaginação de novos usos para velhas ideias; e o teste de conceitos promissores (HARGADON; SUTTON, 2000).

Dentre as práticas mais comuns para a geração de ideias, certamente merece destaque a realização de sessões de brainstorming. Nelas, indivíduos de diversas áreas interagem propondo soluções para algum problema ou oportunidade. Assim, além de não ser absolutamente caótico, o trabalho de geração de ideias não exercita apenas a capacidade criativa individual - ele é colaborativo.

\subsubsection{Construção da estratégia}

As ações prospectivas e de ideação trazem inúmeras possiveis respostas para a pergunta "o que pode ser feito?”. Vários caminhos podem ser vislumbrados e uma gama de possibilidades de próximos passos é aberta. 0 desafio, neste momento, é o de efetivamente construir uma estratégia de inovação para a organização. Esse processo pode ser dividido em três partes: análise (entender profundamente as alternativas), escolha (selecionar em quais opções colocar recursos) e planejamento (decidir como fazer a inovação acontecer) (TIDD; BESSANT; PAVITT, 2008).

A matéria-prima para o processo de análise estratégica é a informação. Nessa etapa, as ideias geradas devem ser avaliadas, categorizadas e comparadas. Para tanto, deve haver um contexto informacional que sirva de pano de fundo, formado pelo entendimento angariado nos processos prospectivos sobre as dimensões mercadológicas e tecnológicas.

Assim, parte fundamental das decisões estratégicas a serem efetuadas reside na existência de um consenso mínimo a respeito de qual a imagem que a organização projeta para o futuro do setor em que atua. É neste ponto que se deve buscar a convergência efetiva da estratégia da corporação com as tendências identificadas. Uma ferramenta importante para essa concepção de um panorama evolutivo é a criação de roadmaps. Por meio deles, é possível se tentar mapear cadência e perspectivas de tempo para tecnologias e produtos.

Os benefícios da criação de roadmaps vão além do roadmap criado. 0 processo é uma oportunidade de reunir pessoas de diferentes áreas para partilharem suas compreensões sobre oportunidades e a evolução do negócio de forma estruturada. Ele estimula a reflexão mais profunda da integração entre tecnologias, produtos e mercados (PHAAL; FARRUKH; PROBERT, 2004).

$\mathrm{Na}$ tentativa de capturar o maior número de oportunidades existentes em meio à complexidade mercadológica e tecnologicamente em que estão inseridas, as empresas empreendem vários esforços simultâneos. Essa gama de iniciativas, entretanto, faz uso da mesma base de recursos. Dessa forma, é latente a necessidade de efetuarem-se escolhas estratégicas. Nesse contexto, a gestão do portfólio emerge como um processo decisório dinâmico por meio do qual uma gama de projetos é constantemente atualizada e priorizada (COOPER; EDGETT; KLEINSCHMIDT, 2001).

\subsubsection{Mobilização de recursos}

Entre a construção da estratégia e a sua implementação há importante passo de definição de quais recursos serão responsáveis pela execução. Quando há atividade de desenvolvimento tecnológico envolvida, essa etapa corresponde ao processo decisório que leva ao outsourcing ou à internalização da P\&D. Esse tipo de decisão tem como pano de fundo a estratégia de competências da organização, que deve se desdobrar num mapeamento de know-how interno e externo, bem como num plano para cobrir eventuais gaps e desenvolver futuras parcerias.

A diversidade de conhecimentos necessários para inovar em indústrias de alta complexidade, a 
dificuldade de angariá-los internamente e a velocidade com que eles evoluem fazem da colaboração com atores externos um imperativo cada vez mais forte (CHESBROUGH, 2003). Na Tabela 2 são caracterizados os diferentes formatos de mobilização de recursos para a inovação.

\subsubsection{Implementação}

A implementação é o coração do processo de inovação. Ela tem como inputs a estratégia, as ideias e os recursos mobilizados. Seus outputs são um produto desenvolvido e um mercado preparado para o lançamento (TIDD; BESSANT; PAVITT, 2008). Dela, espera-se que sejam atendidas as premissas estratégicas para o produto/mercado e que isso ocorra no menor tempo possivel.

Nessa etapa é requerida a maior parte do tempo e do custo. 0 processo é caracterizado por séries de loops de solução de problemas, tanto na dimensão técnica quanto mercadológica. Há envolvimento de todas as dimensões da organização ligada ao produto (P\&D, marketing, produção, assistência ao consumidor, suprimentos, vendas, qualidade). Dessa forma, demanda considerável esforço de coordenação multifuncional e capacidade de execução.

0 desafio de se transformar uma ideia num produto bem-sucedido pode ser visto sob a abordagem de um processo de redução gradual de incerteza por meio de atividades de busca, seleção, experimentação e solução de problemas. Essa visão do processo é bem representada pelo "funil de desenvolvimento", inicialmente proposto por Wheelwright e Clark (1992).

Dois processos principais guiam a implementação de inovações: o processo de desenvolvimento de produtos e o de desenvolvimento de tecnologias. A estruturação típica desses processos é baseada na metodologia de stage-gates desenvolvida por Robert Cooper (2009). 0 método consiste na utilização de "portões" em estágios importantes do projeto e a revisão do mesmo com base em critérios definidos. Apenas em caso de aprovação do projeto ele estará autorizado a passar ao próximo estágio - caso contrário, deve ser abortado ou reorientado (COOPER, 2009).

É possível encontrar avanços significativos nos últimos anos oriundos de trabalhos que abordam esses processos sob a óptica da inovação. Dentre esses progressos, destacam-se: um entendimento mais profundo do processo de desenvolvimento de tecnologia; o avanço de abordagens que promovem a integração entre as diferentes funções nas equipes de projeto; a intensificação do envolvimento antecipado de fornecedores no processo; o amadurecimento dos processos de tomada de decisão dos gates; e a caracterização desses processos de acordo com o grau de inovação (COOPER, 2009).

\subsubsection{Avaliação}

É fundamental que se monitore a performance inovativa a fim de gerenciá-la de forma eficaz. É pela análise de seus resultados e diagnóstico de avanços e deficiências que a organização poderá melhorar continuamente seu processo inovador. Esse processo de avaliação envolve duas dimensões principais: uma com ênfase nos projetos desenvolvidos, na avaliação de seus resultados e incorporação dos aprendizados obtidos ao corpo de conhecimento da organização; outra que monitora o funcionamento do sistema de gestão da inovação como um todo, buscando melhorias sistêmicas para a performance inovativa.

A primeira dimensão engloba práticas que preveem estágio de revisão de projeto após seu lançamento. Essas práticas possibilitam que a organização aprenda com os erros, evite o "reinventar da roda" e acumule as experiências vivenciadas nos projetos. A segunda dimensão, relacionada à avaliação do sistema, possui como desafio a definição de métricas que possibilitem o monitoramento da performance inovativa. Thamhain (2003) destaca a complexidade dessa atividade,

Tabela 2. Formas de mobilização de recursos e aquisição de tecnologias.

\begin{tabular}{|c|c|c|}
\hline Tipo & Vantagens & Desvantagens \\
\hline P\&D formal interna & $\begin{array}{l}\text { Controle; proteção do conhecimento; } \\
\text { aprendizagem }\end{array}$ & Custos e riscos elevados \\
\hline Transferência de tecnologia & $\begin{array}{l}\text { Rápido acesso à tecnologia - desenvolvido por } \\
\text { outrem }\end{array}$ & $\begin{array}{l}\text { Custos; risco de não ser capaz de explorar totalmente a } \\
\text { tecnologia; possiveis restrições contratuais de exploração } \\
\text { da tecnologia }\end{array}$ \\
\hline Contratação de P\&D & Velocidade e foco & Custos; falta de controle; baixa aprendizagem \\
\hline Parceria de $\mathrm{P} \& \mathrm{D} /$ joint venture & Complementaridade de know-how & $\begin{array}{l}\text { Custos; risco de fracasso do relacionamento; aprendizagem } \\
\text { limitada }\end{array}$ \\
\hline Licenciamento & $\begin{array}{l}\text { Rápido acesso à tecnologia - desenvolvido por } \\
\text { outrem }\end{array}$ & $\begin{array}{l}\text { Custos; aprendizagem limitada; possíveis restrições } \\
\text { contratuais de exploração da tecnologia }\end{array}$ \\
\hline Compra & Acesso facilitado & Custos; baixa aprendizagem \\
\hline Aquisição de empresa & Acesso facilitado; controle absoluto & Custos; risco de desajuste cultural \\
\hline
\end{tabular}

Fonte: adaptado de Tidd, Bessant e Pavitt (2008). 
visto que essa medição é fortemente dificultada pela presença de relações complexas entre trabalhos multifuncionais, cadência e percepção de valor.

Adams, Bessant e Phelps (2006) defendem a necessidade de se monitorar a inovação sob a óptica da gestão de processos, e não somente com métricas de seus resultados finais. Para identificarem-se os gargalos "ocultos" na complexa teia da inovação, é fundamental que se monitore a performance de toda a cadeia de valor da inovação da empresa (HANSEN; BIRKINSHAW, 2007).

\subsubsection{Síntese teórica: os processos da gestão da inovação}

Com base nessas contribuições aqui apresentadas, propõe-se aqui síntese conceitual dos processos de gestão da inovação e suas respectivas delimitações. $\mathrm{Na}$ Figura 1 é apresentada essa proposta de consolidação.

Como pode ser notado, a caracterização dos processos é fundamentada em Quadros (2008), e busca-se aqui elencar as principais ferramentas e saídas esperadas dos processos.

\subsection{Contexto organizacional para a inovação}

Não bastam processos bem estruturados para que a inovação ocorra. A execução desses processos estará sempre a cargo de pessoas e é impossível ignorar a relevância de fatores ligados ao modo como essas pessoas se relacionam entre si, com os projetos e com a organização, às configurações de poder que permeiam a empresa e às formas com que as diferentes funções interagem. É necessário um contexto que suporte e promova a atividade inovadora.

Diversos autores já abordaram essa dimensão da inovação, munidos de diferentes enfoques. Rothwell (1992) denomina esse conjunto de fatores organizacionais de "condições corporativas" para a inovação. Tidd, Bessant e Pavitt (2008) usam o termo "fatores contextuais". Nonaka e Takeuchi (1997) defendem a necessidade de um "contexto capacitante" para o trabalho criativo. As próximas seções percorrem a fundamentação teórica dos pilares dessa dimensão: a cultura de inovação; a estrutura e governança organizacionais e os relacionamentos externos.

\subsubsection{Cultura de inovação}

0 desafio de inovar exige a criação de novas ideias, a superação de paradigmas tecnológicos e mercadológicos e um novo olhar sobre a realidade. Não se trata, pois, de um processo mecanicista com entradas e saídas padronizadas e repetitivas. Assim, é impossível minimizar a dimensão intrinsecamente humana do processo inovador: a criatividade para a geração de novas ideias, a experiência para a avaliação

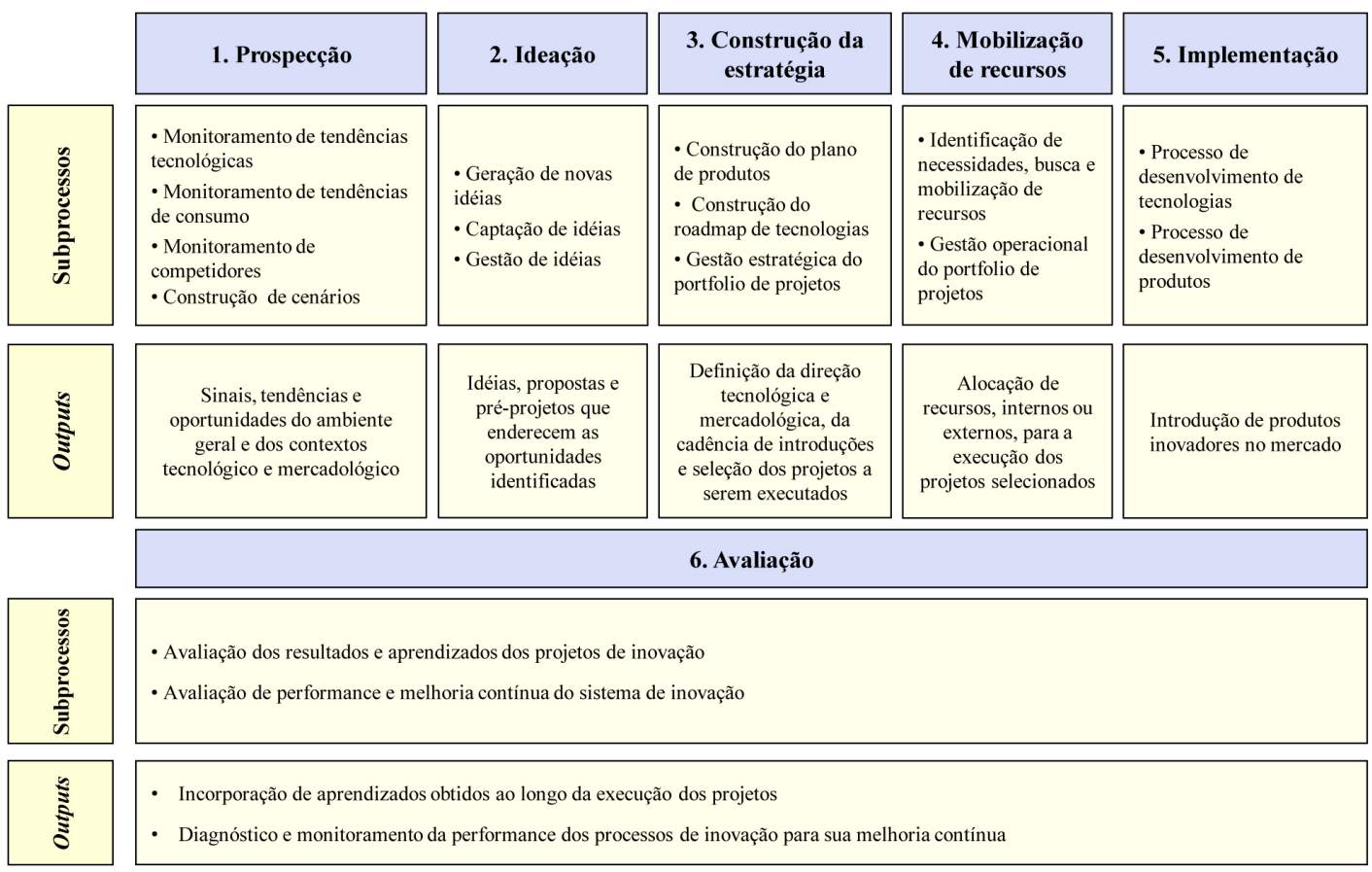

Figura 1. Processos da gestão da inovação. 
de propostas, a intuição para a tomada de decisões com risco, a persistência para novas tentativas após o fracasso. Este cenário faz com que o contexto social e cultural da organização desempenhe importante papel no processo de inovação.

É possível identificar três eixos principais que participam da construção de um ambiente inovador: as práticas de gestão de pessoas, expressas pelas políticas de gestão de recursos humanos vigentes e do estilo de liderança de pessoas exercido pelos gestores de equipes; e a orientação estratégica à inovação. Essas dimensões são responsáveis pela criação de cultura propícia à inovação: flexível, diversificada, tolerante ao risco, à incerteza e ao erro, que conceda autonomia, que estimule a criatividade, que reconheça a busca pela inovação como valor organizacional (KING; ANDERSON, 2002).

No campo da gestão de pessoas, destacam-se entre as políticas formais de gestão de recursos humanos aquelas ligadas ao recrutamento e à seleção de novos profissionais e às políticas de carreira e reconhecimento. As primeiras podem contribuir na busca por pessoas com habilidades criativas e que tragam diversificação às equipes (STRINGER, 2000). A diversidade de experiências é fundamental para se potencializar a performance criativa de grupos, principalmente durante as fases de divergência e expansão de ideias e propostas (LEONARD; SENSIPER, 1998). 0 recrutamento que busca essa heterogeneidade pode colaborar trazendo pessoas que exercerão o papel de "dissidentes" de consensos estabelecidos. Segundo Nemeth (1997), elas são fundamentais para atividades coletivas: estimulam pensamentos mais complexos, melhoram o processo de resolução de problemas e incentivam a construção de novas abordagens.

É amplamente reconhecida a importância da motivação para a inovação (THAMHAIN, 2003). É com base nessa premissa que deve ser enxergada a influência das políticas de carreira e reconhecimento na performance inovadora. Os resultados esperados desses fatores na criação do contexto inovador podem ser divididos em três pilares principais: motivação para o trabalho criativo, para o trabalho coletivo e para a busca pelo próprio desenvolvimento do profissional.

Para que se compreenda a dinâmica da motivação para a criatividade, faz-se necessário entender os fundamentos da motivação profissional. Existem duas formas básicas de motivação: a extrínseca e a intrínseca. A primeira está relacionada aos estímulos externos que afetam a relação do indivíduo com o trabalho - por exemplo, a recompensa financeira. Mas é na motivação intrínseca, relacionada à ligação pessoal do indivíduo com o trabalho, que reside o verdadeiro potencial para a criatividade. É pela paixão pelo conteúdo intrínseco de suas atividades, por enxergar uma parcela de realização pessoal no seu dia a dia de trabalho, que os indivíduos exercitam na plenitude sua capacidade de romper a fronteira do que já existe (AMABILE, 1998).

Além da contribuição dos indivíduos para a atividade criativa, deve-se fomentar motivação pelo trabalho colaborativo para a inovação. Leonard e Sensiper (1998) defendem a importância do conhecimento tácito para a inovação e destacam a relevância do componente social para que ele possa ser canalizado para o desenvolvimento criativo.

A busca do próprio desenvolvimento por parte dos colaboradores também é fator de influência da motivação profissional dos colaboradores (SHIRAHADA; NIWA, 2007). Assim, as políticas de capacitação e o teor da gestão de equipes inovadoras devem buscar proporcionar essa perspectiva de evolução.

A dinâmica da criação de novos conhecimentos é composta por ritmos de busca e de seleção, fases de exploração e de síntese, ciclos de pensamentos divergentes seguidos por etapas de convergência (LEONARD; SENSIPER, 1998). Essa complexidade e não linearidade do processo de criação de conhecimentos trazem dificuldades à gestão da inovação. Além de serem as principais responsáveis pela incerteza intrínseca à inovação, elas exigem dos gestores: (1) uma compreensão sobre o ambiente social de suas equipes; (2) uma leitura verossímil dos potenciais e dos perfis motivacionais de cada indivíduo; e (3) um entendimento sobre a natureza e das fontes do know-how incorporado aos seus produtos.

Dessa forma, os gestores devem se enxergar como guardiões do suporte ao trabalho criativo dos times, garantindo a disponibilidade de recursos, a estabilidade das metas e prioridades e o envolvimento da gerência sênior sempre que necessário (THAMHAIN, 2003). Esse suporte provê autonomia e infraestrutura organizacional para que os profissionais possam exercer plenamente sua atividade criativa.

Há constante necessidade de se ajustar a tensão entre criatividade e disciplina no processo inovador. Dessa forma, um dos papéis fundamentais da gestão de pessoas neste processo é ditar o nível de controle sobre as atuações individuais e as iniciativas. Há consenso de que certo grau de liberdade e flexibilidade é indispensável para a produtividade de times inovadores (BONNER; RUEKERT; WALKER JUNIOR, 2002). Mas é igualmente verídico que alguma forma de controle deve existir a fim de evitarem-se: (1) desvios para caminhos desalinhados com a estratégia; (2) que persigam opções de projetos que vão além das capacidades da organização; (3) que levem a debates improdutivos e intermináveis; ou (4) que sigam execução descontrolada, demasiadamente 
fora do prazo e/ou do orçamento (PEREZ-FREIJE; ENKEL, 2007).

Numa dimensão mais estratégica deste suporte dos gestores, é igualmente importante que haja força sustentando a busca pela inovação como prioridade estratégica da alta direção da organização. A organização deve apresentar uma base de poder explícita e abrangente voltada para a inovação do produto, ou não haverá força geradora e energia para o desenvolvimento contínuo de inovações (DOUGHERTY; HARDY, 1996). Para tanto, a alta direção deve explicitar seu compromisso com a inovação pela sua presença, patrocínio e envolvimento nas iniciativas e fóruns de inovação. Somente dessa forma se instilará o reconhecimento da inovação como intenção estratégica e se sustentará uma cultura de incentivo à atividade inventiva e aos valores que permeiam o ambiente inovador.

\subsubsection{Estrutura organizacional e governança para a inovação}

A inovação não acontece espontaneamente. É necessário poder organizacional para facilitar, conduzir e decidir. Ela depende de forte orquestração entre as funções, como marketing, P\&D e produção, num ambiente que envolve dependências intraorganizacionais complexas. Esse cenário exige que a organização das equipes e a divisão de papéis e poderes sejam aderentes ao desafio de inovar. Para tanto, deve haver estrutura de poder e governança adequadas e com compromisso explícito com a inovação (HARDY; DOUGHERTY, 1997).

Para se entender a influência do aspecto estrutural na performance inovativa é necessário compreender a complexidade das organizações que inovam em produto. Nelas, há necessidade de distribuir as responsabilidades para as equipes em meio a diferentes dimensões do trabalho, como os níveis de especialização e os horizontes de tempo (BROWN; EISENHART, 1994).

Com relação aos níveis de especialização, as organizações devem articular de forma inteligente a tensão existente entre a estruturação organizada em torno do produto e aquela baseada nas especialidades funcionais. É necessário investir energia para encontrar configurações estruturais que propiciem o acúmulo do conhecimento funcional e promova a integração multifuncional necessária para a execução plena dos projetos (HENDERSON, 1994).

Se, por um lado, a importância de se deter a técnica funcional em profundidade é óbvia, pois remete à competência na execução das diversas dimensões do produto, também já foi provado que a capacidade de trabalhar as funções de forma integrada é decisiva para a competência em inovar. Parthasarthy e Hammond (2002) comprovam empiricamente a influência positiva da integração funcional na performance inovativa.

Essa integração é fundamental para a execução simultânea de atividades, o que reduz os tempos de desenvolvimento. Ela é obtida pela: (a) montagem das equipes de projeto com representantes de cada uma das funções; (b) utilização de metas de projeto e sistemas de reconhecimento coletivos; e (c) participação constante da alta liderança na promoção desta integração, eliminando barreiras entre as áreas (COOPER, 2009).

No que tange aos diferentes horizontes de tempo, as organizações devem ser capazes de operar simultaneamente a curto e longo prazos a melhoria incremental e a ruptura. Devem continuamente evoluir sua plataforma de produtos, mas mantendo esforços na construção das novas gerações, algumas delas que rompam em absoluto com a configuração presente.

0 fato de possuírem uma quantidade limitada de recursos faz da priorização de esforços uma tarefa diária das organizações. Por estarem submetidas à pressão por resultados de curto prazo, há forte risco de se enviesar a alocação de esforços para iniciativas menos arriscadas e ligadas a retornos financeiros rápidos (SALAMAN; STOREY, 2002). Entretanto, ao se abdicar das "apostas" de maior incerteza, corre-se o risco de se conviver com linhas de produtos estagnadas e de ser ultrapassado por avanços disruptivos da concorrência (BAYUS, 1998).

Tushman e Anderson (1997) propõem o termo “ambidestras” para as organizações que possuem arquiteturas capazes de efetuar simultaneamente inovações nessas diversas dimensões de especialização e tempo. Essas organizações, entretanto, carregam parcela intrínseca de instabilidade. Há o frequente risco de unidades tradicionais sabotarem unidades mais empreendedoras. Frequentemente, a eficiência e a inovação incremental de hoje sufocam a inovação radical de amanhã (TUSHMAN; ANDERSON, 1997).

Além dessa complexidade interna, a estrutura organizacional, voltada para a inovação, deve ser dinâmica. Produtos inovadores quebram o statu quo, isto é, rompem os paradigmas técnicos e mercadológicos vigentes - o que tem forte impacto interno na organização. Dessa forma, a atuação de grupos de trabalho, as lideranças e as estruturas de poder são fortemente influenciadas por inovações. Isso exige que a liderança da implementação de uma inovação tenha habilidades de gerenciamento da mudança e patrocínio para vencer as resistências que certamente surgirão.

A organização deve apresentar uma base de poder explícita voltada para a inovação, ou não haverá 
força geradora para o desenvolvimento sustentado de inovações. Para tanto, a alta direção da empresa deve tornar a estrutura de poder da empresa apta para não ser dependente de esforços heroicos e sucessos ocasionais (DOUGHERTY; HARDY, 1996).

\subsubsection{Relacionamentos com o ambiente externo}

A inovação de produto pode ser enxergada como resultado de um desenvolvimento tecnológico que aproveita uma oportunidade mercadológica. Sob essa óptica, é impossível ignorar a importância de a organização estar efetivamente conectada ao meio externo para ser inovadora. Isso de deve à necessidade de adquirir conhecimentos tecnológicos - visto que dificilmente os produzirá integralmente de maneira interna - e de mapear e avaliar tendências e oportunidades de mercado.

As oportunidades para essa aprendizagem com o ambiente ocorrem por meio de relacionamentos entre a empresa e atores externos. Para tanto, é fundamental que a empresa cultive fronteiras organizacionais permeáveis, fundamentadas no estabelecimento de interações contínuas com fornecedores, clientes, usuários finais, institutos de pesquisa e outros parceiros (LEONARD, 1998).

0 avanço das abordagens de Open Innovation, propostas inicialmente por Chesbrough (2003), reforça o declínio do foco na atividade inovativa centrada no ambiente interno da organização. Segundo o autor, essa tendência é sustentada pelo alargamento da base de produtores de conhecimento e pela maior mobilidade desses "trabalhadores do conhecimento", tornando mais difícil a tarefa de se apropriar e controlar a fronteira do conhecimento internamente (CHESBROUGH, 2003). Deve-se, assim, entender a organização inovadora como uma célula inserida num arranjo dinâmico composto por diversos atores, coletivos e individuais, interconectados por contínuas trocas de informações e trabalhando para comercializar novos conhecimentos (DODGSON; GANN; SALTER, 2006; BRANNBACK, 2003).

Powell (1998) defende que a visão das organizações e suas redes como sistemas de produção, síntese e distribuição de ideias e reconhece que o sucesso das empresas está fortemente ligado à profundidade das interações da empresa com organizações de diversos tipos. Assim, mais do que o estabelecimento de link sólido e disciplinado com uma única fonte de conhecimento, faz-se necessário estabelecer vínculos reais com uma gama diversificada de instituições que possuam interesses em determinada área de conhecimento.

A identificação de fontes estratégicas e a abertura de canais de obtenção de conhecimentos constituem etapas importantes do processo de aprendizado externo. Mas esses passos são insuficientes para que a organização incorpore know-how externo, pois muito do conhecimento técnico se apresenta tácito - uma mistura indissolúvel de processo e experiência.

É de suma importância que a empresa possua a habilidade necessária para absorver os conhecimentos desejados. Segundo Leonard (1998), a capacidade de absorção do saber externo de uma empresa está ligada à competência em se reconhecer o valor das informações externas, assimilá-las de forma efetiva e aplicá-las com fins comerciais.

\subsubsection{Sintese teórica: o contexto organizacional para a inovação}

Na Figura 2 são organizados os elementos envolvidos na construção das condições organizacionais para a inovação e os resultados esperados de cada um deles.

\subsection{Recursos para a inovação}

A execução dos processos de inovação, em meio ao contexto estabelecido, se dá pela utilização de recursos organizacionais. Como visto, para que a inovação ocorra é necessária uma série de atividades, operacionais e estratégicas, que consomem recursos dos mais variados tipos. Utiliza-se aqui a categorização desses recursos para a inovação proposta por Quadros (2008):

- Recursos financeiros: envolvem o montante disponibilizado para a remuneração dos profissionais ligados à inovação, para os investimentos em infraestrutura de P\&D e para aquisição de tecnologia.

- Recursos de infraestrutura: engloba a infraestrutura para as atividades de P\&D como a existência de laboratórios de pesquisa e certificação de produtos, softwares para projetos de engenharia e plantaspiloto. Esse tipo decorre do acúmulo da alocação de recursos financeiros e refletem o compromisso da empresa com a inovação ao longo do tempo (QUADROS, 2008).

- Recursos intangíveis: trata dos recursos efetivamente responsáveis pela capacidade inovativa de uma organização. Ela engloba todo o corpo de conhecimentos tácitos e explícitos, acumulados na empresa. Dessa forma, envolve, além das competências incorporadas em seus indivíduos e grupos, os ativos de conhecimentos codificados em seus registros 


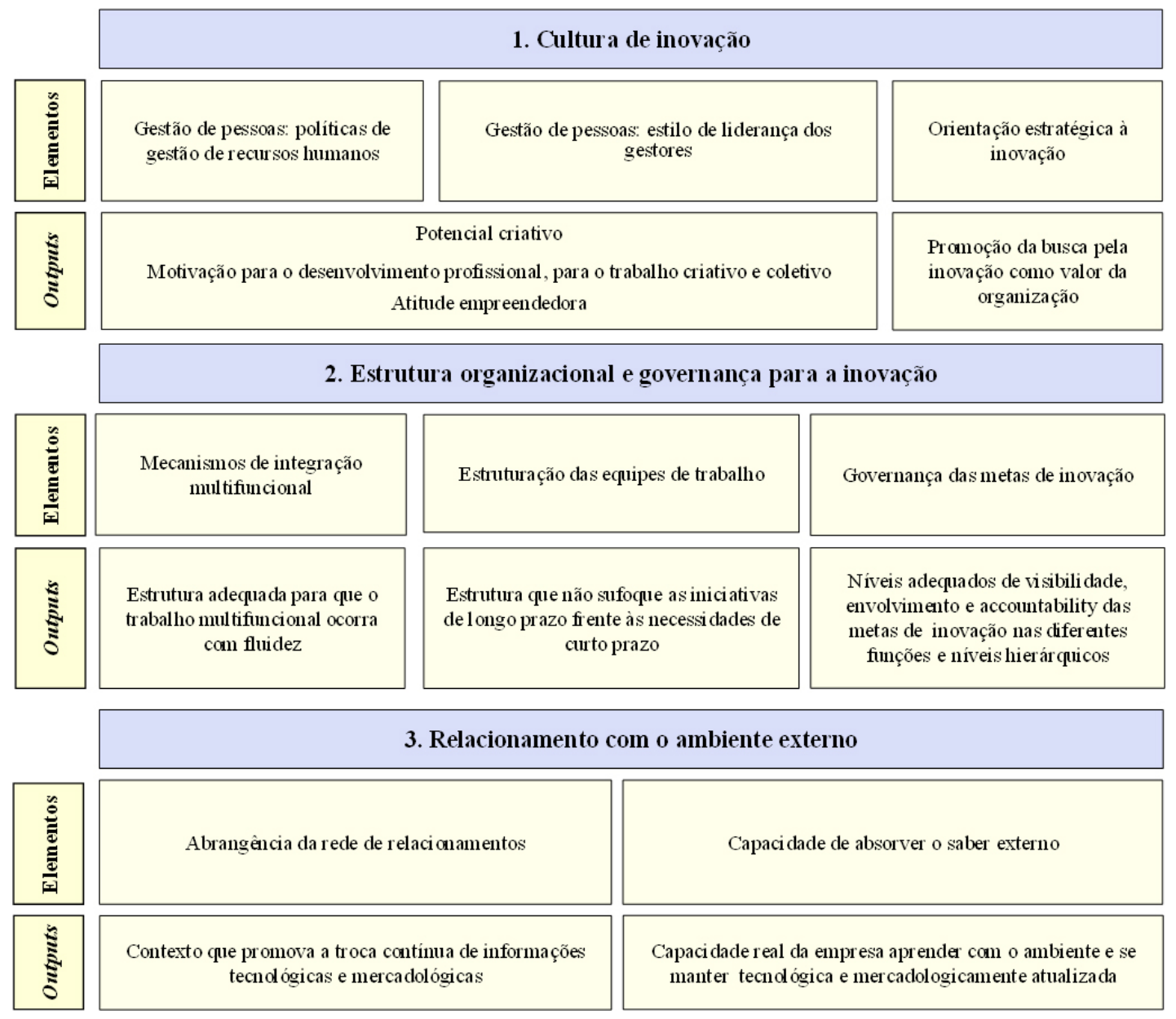

Figura 2. Contexto organizacional para a inovação.

internos, sejam eles apropriáveis ou não sob a forma de propriedade intelectual (QUADROS, 2008).

\subsection{Sintese teórica: modelo integrado para a gestão da inovação}

Com base na fundamentação e nas sínteses apresentadas até aqui, propõe-se modelo integrado para a gestão da inovação de produto em empresas de grande porte organizado em torno de três dimensões fundamentais: processos, contexto organizacional e recursos. A construção desse modelo, apresentada na Figura 3, tem como bases estruturais os modelos de Tidd, Bessant e Pavitt (2008) e Quadros (2008), e o método construtivo se valeu de exercício teórico indutivo pautado pela combinação e síntese dos elementos apresentados na revisão bibliográfica das seções anteriores.

É importante mencionar que os conceitos apresentados nesta pesquisa e nesse modelo são oriundos majoritariamente de teorias organizacionais voltadas ao estudo das empresas de grande porte e, dessa forma, não contemplam especificidades típicas das teorias voltadas para o estudo de pequenas empresas. No que tange ao tipo de indústria, as pesquisas que alimentam a construção deste modelo são suficientemente abrangentes para contemplar questões ligadas a diversas realidades, com a ressalva de se haver conteúdos bastante diversos dentro de cada dimensão para cada setor. Por exemplo, em segmentos mais orientados por inovação do tipo technologypush, pode-se esperar um peso maior de processos de prospecção tecnológica e de desenvolvimento de tecnologias, alocação de recursos em P\&D, e a importância de cultura organizacional mais orientada à criação técnica.

Há elevada interação entre os elementos das diferentes dimensões do modelo. Para que a inovação ocorra, os recursos devem ser explorados pelos processos em meio ao contexto organizacional. 0 sucesso e a cadência de um sistema de gestão 


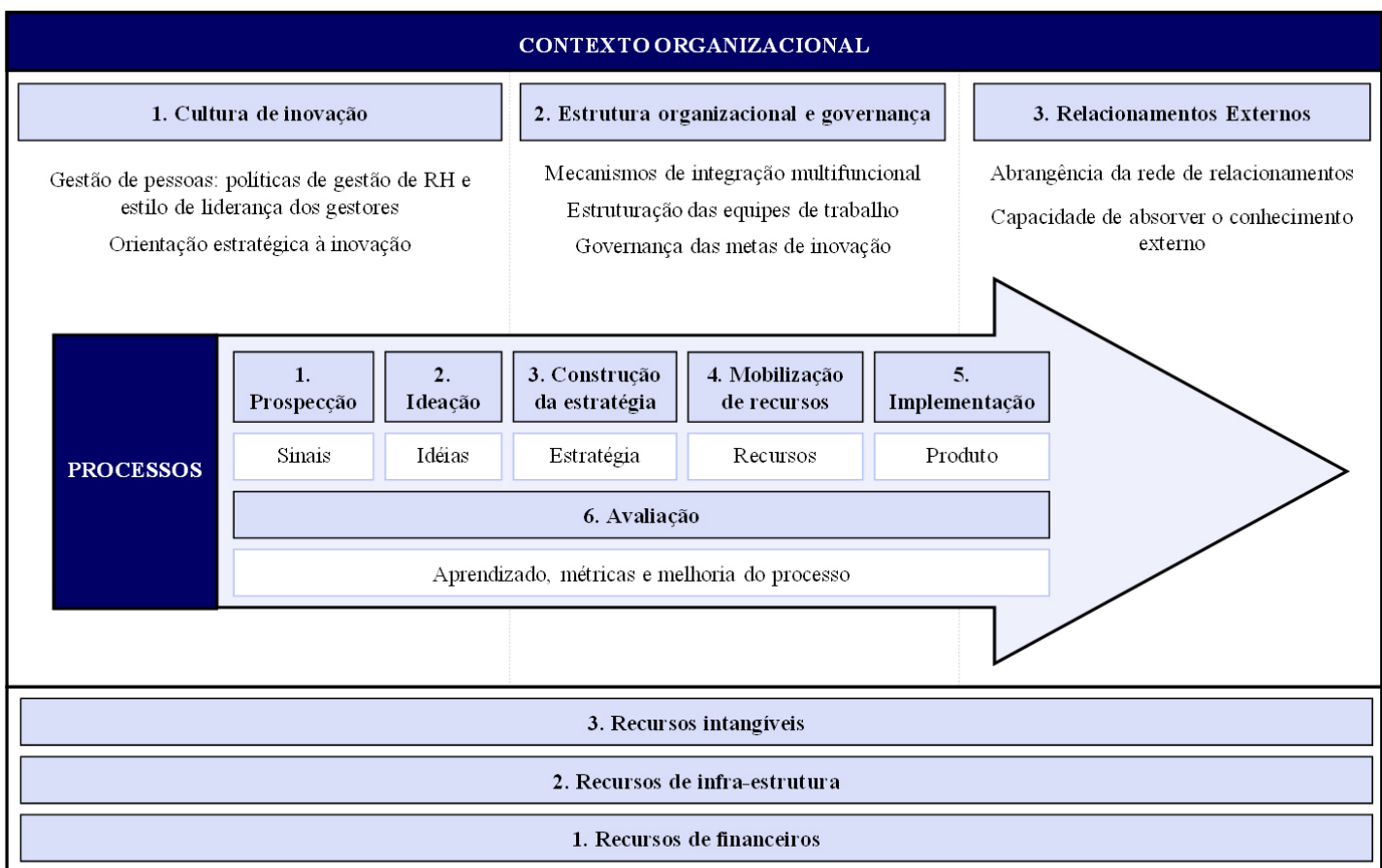

RECURSOS

Figura 3. Modelo integrado da gestão da inovação.

da inovação dependem, assim, da qualidade e da adequabilidade dos elementos que compõem essas três dimensões.

Os recursos são condições necessárias para que a inovação ocorra - sem eles, não há inovação. Os processos são guias que buscam sistematizar e disciplinar o fluxo de exploração dos recursos. Apesar das idas e vindas e da incerteza inerentes à inovação, eles trazem em seu conjunto uma linha mestra para a condução do desenvolvimento de inovações. A institucionalização dos processos provê cadência e propicia o monitoramento da performance inovativa em meio ao progresso dos esforços. 0 contexto organizacional é responsável por criar o meio adequado e prover sentido e consistência à exploração dos recursos por meio dos processos.

A relação entre os recursos e os processos de inovação deriva da natureza de cada um dos processos. Os recursos de infraestrutura de $P \& D$ são importantes na etapa de implementação, enquanto a infraestrutura de tecnologia da informação atua como um catalisador de praticamente todas as etapas. A relação dos recursos financeiros é indireta: é por meio deles que a organização provê os recursos de infraestrutura citados e a capacidade de obtenção de tecnologias, além de garantir a manutenção do corpo de profissionais que detém os recursos intangiveis.
Os recursos intangíveis são vitais para absolutamente todas as etapas. lsso se deve ao fato de todas elas apresentarem, em maior ou menor grau, parcela de incerteza e necessidade de know-how para serem executadas em sua plenitude. Na Tabela 3 são sistematizadas as principais competências demandadas em cada etapa.

A relação entre os processos e o contexto organizacional para a inovação é complexa. Na Tabela 4 é apresentada uma proposição de relacionamentos entre os elementos dessas dimensões. A proposta tem como base a fundamentação teórica apresentada neste capítulo e busca elencar de que formas as variáveis do contexto organizacional podem influenciar os processos de inovação.

Efetuadas a síntese teórica da gestão da inovação e a proposição de possíveis relacionamentos entre os elementos do modelo integrado, a seção que se segue aborda os principais desafios encontrados pelas organizações para ampliar sua capacidade inovativa.

\section{Desafios da inovação}

A necessidade de inovar coloca as organizações em meio a um grande desafio. A inovação depende de um conjunto intrincado de interações entre elementos tecnológicos e mercadológicos. Promovê-la de forma sistemática no contexto empresarial demanda a 
Tabela 3. Os processos de inovação e os recursos intangíveis.

Processos

1. Prospecção

2. 1deação

3. Construção da estrategia

3. Construção da estratégia

4. Mobilização de recursos

5. Implementação

6. Avaliação

Fonte: elaborado pelo autor.
Relação com os principais recursos intangíveis para a inovação

As atividades prospectivas exigem habilidade de buscar, analisar e interpretar fragmentos de informações de elevado nível de incerteza, captadas em ambientes turbulentos.

0 processo demanda capacidade criativa para a proposição de novas ideias pela análise de oportunidades mercadológicas, conhecimentos sobre o consumidor e sinais tecnológicos.

A construção estratégica demanda competência para avaliar e escolher caminhos dentre uma gama de possibilidades. Por envolver a tomada de decisões de alto impacto, baseadas em cenários de alta incerteza, exige elevada capacidade analítica e intuição dos envolvidos.

A mobilização de recursos exige conhecimentos mínimos sobre o tipo e a quantidade de recursos necessários para a execução, além da capacidade de gerenciar a alocação dos mesmos.

A implementação exige profundo conhecimento técnico-funcional sobre tecnologias, mercado e consumidores. Demanda conhecimentos tácitos para a resolução de problemas novos e exige competências para o gerenciamento de projetos e coordenação multifuncional.

A avaliação exige de gestores da inovação a visão sistêmica para a criação de métricas aderentes aos processos da organização e capacidade analítica para monitorar a performance desses processos de forma eficaz e direcionada à melhoria sistêmica.

Tabela 4. Os processos de inovação e o contexto organizacional para a inovação.

Processos

Relação com elementos do contexto organizacional para a inovação

Estrutura e governança: a atividade prospectiva consome recursos organizacionais e, por não gera resultados imediatos, exige forte patrocínio para sua plena execução. Por estar ligada à coleta de informações multidisciplinares, demanda envolvimento de diversas áreas para a análise dos sinais captados. Assim, a definição de responsabilidades é fundamental para sua eficácia.

1. Prospecção

Relacionamentos externos: a qualidade da atividade prospectiva está fortemente relacionada à capacidade da organização de "ler" o ambiente externo em suas dimensões tecnológicas e mercadológicas. Para tanto, a interação da organização com atores externos potencializa a competência na captura e interpretação das tendências tecnológicas e mercadológicas.

Gestão de pessoas: o potencial criativo para a geração de ideias novas é fortemente influenciado pela diversidade, motivação, abertura ao erro e autonomia, elementos caracterizados em boa parte pelas práticas de gestão de pessoas em vigor.

Estrutura e governança: a geração de ideias envolve atividades multifuncionais para que se potencialize

2. 1deação o vigor criativo pela diversidade e da visão holística. A definição de papéis nas iniciativas de geração e gerenciamento de ideias é essencial para a eficácia do processo.

Relacionamentos externos: a interação próxima com clientes e consumidores promove conhecimento mais profundo sobre suas realidades e, assim, potencializa a capacidade de geração de propostas aderentes às suas necessidades menos explícitas. Além disso, ganham força abordagens de Open Innovation, em que a ideação é compartilhada com agentes externos.

Gestão de pessoas: a seleção estratégica envolve, muitas vezes, a opção por alternativas de risco elevado. Dessa forma, a tolerância à incerteza e à forma como a organização lida com o erro moldam seu perfil de construção estratégica.

3. Construção da estratégia Estrutura e governança: a construção de estratégias de inovação integradas à estratégia de negócios demanda envolvimento da alta direção e forte trabalho multifuncional. Deve-se integrar a visão de várias áreas e buscar consenso acerca dos caminhos futuros. A definição dos poderes e papéis, bem como dos fóruns de tomada de decisões, é peça-chave nesse processo.

Estrutura e governança: o controle da alocação dos recursos e das prioridades de projetos deve ser executado de forma sistemática com participação das respectivas funções envolvidas.

4. Mobilização de recursos Relacionamentos externos: a abrangência da rede e a qualidade dos relacionamentos externos propiciam maior capacidade de identificar recursos externos para a implementação de inovações.

Gestão de pessoas: os níveis de autonomia e tolerância à incerteza podem influenciar a velocidade de execução dos projetos. Ambientes de abertura e diversidade podem potencializar a capacidade de resolução de problemas novos, que são típicos nessa fase.

Estrutura e governança: a execução de projetos de desenvolvimento de produtos demanda intensa

5. Implementação orquestração multifuncional e suporte da alta direção para a remoção de entraves organizacionais. A composição das equipes de projeto e a autoridade concedida aos gerentes de projeto perante as funções são variáveis críticas para a consistência da execução dos projetos.

Relacionamentos externos: relacionamentos maduros com agentes externos colaboram na execução de projetos quando há parceria para utilização de recursos. Além disso, uma rede abrangente de relacionamentos pode ser útil para a resolução ágil de problemas desconhecidos.

Gestão de pessoas: os sistemas de reconhecimento e recompensa devem contemplar as métricas de inovação

para que indivíduos e grupos estejam conectados à estratégia inovativa.

6. Avaliação
Estrutura e governança: a organização deve apresentar rotinas claras para o monitoramento da performance inovativa. Os resultados devem estar integrados aos indicadores da empresa. As análises geradas devem ser compartilhadas com as funções e devem servir de input para a melhora contínua. 
conjunção de fatores humanos e organizacionais integrados a essas dimensões técnicas e de mercado.

É evidente que o ambiente concorrencial e tecnológico do setor, o porte da organização e o sistema nacional de inovação em que uma organização está envolvida são fatores que influenciam a caracterização dos seus obstáculos à inovação. Entretanto, não se pode ignorar a dimensão interna à organização, ligada à forma como ela estrutura e executa seu sistema de gestão da inovação para compreender suas dificuldades específicas. Nesse sentido, as dificuldades para inovar são encaradas aqui como desafios de gestão - sem desprezar a influência das variáveis moderadoras externas nesse processo, obviamente.

O desafio do gerenciamento da inovação é complexo. Essa complexidade deriva de características fundamentais do processo: envolve elevado patamar de risco e incerteza; exige envolvimento e mobilização de várias áreas da organização; apresenta uma gama de processos internos que têm subprodutos não padronizados; exige monitoramento constante e inteligente do ambiente; envolve a alocação e a gestão de recursos de alto grau de especialização; exige agilidade estrutural para a contínua reconfiguração interna da organização; exige entendimento da natureza de seu principal recurso, o conhecimento (TIDD; BESSANT; PAVITT, 2008; THAMHAIN, 2003; NONAKA; TAKEUCHI, 1997).

Na literatura acadêmica, há dois tipos de trabalhos que abordam os obstáculos à inovação. No primeiro estão pesquisas que abordam individualmente cada um dos temas relacionados à gestão da inovação e, ao fazê-lo, discutem os desafios relacionados e as boas práticas prescritas para superá-los. Boa parte da fundamentação teórica aqui construída foi baseada em trabalhos como estes, que muitas vezes tratam dos obstáculos de forma pouco explícita.

No segundo, mais reduzido, encontram-se os trabalhos que têm os obstáculos à inovação como tema central. É exemplo a obra de Galia e Legros (2004), que aborda os obstáculos, porém sob enfoque de compreendê-los à luz das políticas públicas da região em que estão inseridos. Na Tabela 5 são elencadas as principais dificuldades internas à organização encontradas na literatura.

Sugere-se aqui a abordagem desses obstáculos à luz do modelo integrado para a gestão da inovação construído. Propõe-se que essas dificuldades devem ser entendidas como desafios de gestão da inovação, sendo esta constituída pelas três dimensões propostas. Na Tabela 6 são sistematizados, com base na fundamentação teórica apresentada, os relacionamentos entre os obstáculos e os elementos do modelo integrado.

\section{Considerações finais}

A performance inovativa é obtida pela combinação complexa de elementos humanos, organizacionais, tecnológicos e mercadológicos. Esse caráter multidimensional, somado à presença intrínseca de risco e à necessidade de exploração de ativos tangiveis e intangíveis, faz da inovação um enorme desafio de gestão. A disponibilidade de recursos valiosos e raros, tangíveis e intangíveis, é necessária, mas não garante a inovação. Trata-se da matéria-prima, que deve ser transformada em valor.

Encarar esse desafio sob o ponto de vista processual é um importante passo. Os processos de gerenciamento da inovação são guias que disciplinam e orientam o fluxo de transformação de oportunidades em produtos inovadores pela utilização dos recursos. A constante presença da incerteza em meio às atividades inovadoras torna os processos que as organizam peças fundamentais para que a inovação não esteja condenada a ocorrer "por acaso”. Essa estruturação processual se traduz em rotinas que possibilitam a existência de uma cadeia de valor da inovação na

Tabela 5. Principais dificuldades internas à inovação.

\begin{tabular}{|c|c|c|c|}
\hline Obstáculo à inovação & Referências & Obstáculo à inovação & Referências \\
\hline $\begin{array}{l}\text { Dificuldade para lidar com a incerteza } \\
\text { e o risco }\end{array}$ & Sharma (1999) & $\begin{array}{l}\text { Dificuldade para conectar o portfólio } \\
\text { de projetos aos objetivos estratégicos }\end{array}$ & $\begin{array}{l}\text { Cooper, Edgett e Kleinschmidt } \\
\text { (2001) }\end{array}$ \\
\hline Falta de informações sobre o mercado & \multirow{3}{*}{ Galia e Legros (2004) } & $\begin{array}{l}\text { Dificuldade para transformar as ideias } \\
\text { selecionadas em produtos }\end{array}$ & Cooper (2009) \\
\hline Falta de informações sobre tecnologias & & $\begin{array}{l}\text { Dificuldade para medir os resultados e } \\
\text { a performance em inovação }\end{array}$ & Adams, Bessant e Phelps (2006) \\
\hline Falta de informações sobre o consumidor & & $\begin{array}{l}\text { Dificuldade para gerar ideias } \\
\text { verdadeiramente novas }\end{array}$ & Nemeth (1997) \\
\hline $\begin{array}{l}\text { Dificuldade de avaliar e selecionar as } \\
\text { melhores ideias }\end{array}$ & Sharma (1999) & $\begin{array}{l}\text { Dificuldade para efetuar a orquestração } \\
\text { das diversas áreas }\end{array}$ & Thamhain (2003) \\
\hline
\end{tabular}

Fonte: elaborado pelo autor. 
Tabela 6. Parte 1. A gestão da inovação e seus desafios: possíveis relacionamentos.

\begin{tabular}{|c|c|c|c|}
\hline \multirow{2}{*}{$\begin{array}{l}\text { Obstáculos à } \\
\text { inovação }\end{array}$} & \multirow[b]{2}{*}{ Sintomas típicos } & \multicolumn{2}{|c|}{ Elementos do sistema de gestão da inovação possivelmente relacionados } \\
\hline & & Processos de inovação & $\begin{array}{c}\text { Contexto organizacional para a } \\
\text { inovação }\end{array}$ \\
\hline $\begin{array}{l}\text { Dificuldade para } \\
\text { lidar com risco e } \\
\text { incerteza }\end{array}$ & $\begin{array}{l}\text { - Incapacidade de manter esforços em } \\
\text { iniciativas de maior prazo e risco em } \\
\text { virtude da pressão por resultados de } \\
\text { curto prazo } \\
\text { - Sensação excessiva de insegurança e } \\
\text { desconforto perante a incerteza }\end{array}$ & $\begin{array}{l}\text { - Processos demasiadamente } \\
\text { engessados, despreparados para } \\
\text { contemplar a incerteza típica da } \\
\text { inovação }\end{array}$ & $\begin{array}{l}\text { - Liderança não preparada e/ou não } \\
\text { desafiada para lidar com risco } \\
\text { - Promoção de ambiente de baixa } \\
\text { tolerância ao erro por parte da liderança } \\
\text { - Estrutura organizacional que inibe a } \\
\text { convivência de esforços de diferentes } \\
\text { horizontes de prazo e risco }\end{array}$ \\
\hline $\begin{array}{l}\text { Falta de } \\
\text { informaações sobre } \\
\text { tecnologias }\end{array}$ & $\begin{array}{l}\text { - Incerteza excessiva na avaliação de } \\
\text { tecnologias } \\
\text { - Trajetória tecnológica reativa, estando } \\
\text { sempre atrás dos concorrentes }\end{array}$ & $\begin{array}{l}\text { - Processo de prospecção } \\
\text { tecnológica inexistente ou não } \\
\text { efetivo }\end{array}$ & $\begin{array}{l}\text { - Carência de relacionamentos externos } \\
\text { com agentes tecnológicos relevantes }\end{array}$ \\
\hline $\begin{array}{l}\text { Falta de } \\
\text { informações sobre } \\
\text { o mercado }\end{array}$ & $\begin{array}{l}\text { - Incerteza excessiva na avaliação de } \\
\text { oportunidades de mercado } \\
\text { - Estratégia de mercado reativa, sendo } \\
\text { sempre surpreendida pelos concorrentes }\end{array}$ & $\begin{array}{l}\text { - Processo de mapeamento de } \\
\text { oportunidades mercadológicas } \\
\text { inexistentes ou não efetivo } \\
\text { - Inteligência competitiva ineficaz }\end{array}$ & $\begin{array}{l}\text { - Carência de relacionamentos mais } \\
\text { profundos com clientes/consumidores }\end{array}$ \\
\hline $\begin{array}{l}\text { Falta de } \\
\text { informações } \\
\text { sobre os clientes/ } \\
\text { consumidores }\end{array}$ & $\begin{array}{l}\text { - Incerteza excessiva na avaliação de } \\
\text { benefícios desejados por clientes } \\
\text { - Estratégia reativa de desenvolvimento } \\
\text { de produtos, sendo sempre } \\
\text { surpreendida pelos concorrentes }\end{array}$ & $\begin{array}{l}\text { - Processo de prospecção de } \\
\text { tendências de consumo inexistente } \\
\text { ou não efetivo }\end{array}$ & $\begin{array}{l}\text { - Carência de relacionamentos mais } \\
\text { profundos com clientes/consumidores }\end{array}$ \\
\hline $\begin{array}{l}\text { Dificuldade para } \\
\text { gerar ideias } \\
\text { verdadeiramente } \\
\text { novas }\end{array}$ & $\begin{array}{l}\text { - Ambiente "viciado" pelas mesmas } \\
\text { ideias de sempre } \\
\text { - Impressão de que não há "nada mais } \\
\text { a ser criado" no segmento }\end{array}$ & $\begin{array}{l}\text { - Processo de ideação e execução } \\
\text { de atividades de geração de ideias } \\
\text { ausentes ou não efetivos } \\
\text { - Baixa eficácia de processos } \\
\text { prospectivos gera falta de contexto } \\
\text { informacional para a geração de } \\
\text { boas ideias }\end{array}$ & $\begin{array}{l}\text { - Baixa diversidade interna } \\
\text { - Promoção de ambiente de baixa } \\
\text { tolerância ao erro e controle excessivo } \\
\text { por parte da liderança } \\
\text { - Baixo estímulo à atividade criativa: } \\
\text { reconhecimento e atenção da liderança } \\
\text { escassos }\end{array}$ \\
\hline
\end{tabular}

Tabela 6. Parte 11. A gestão da inovação e seus desafios: possíveis relacionamentos.

\begin{tabular}{cccc}
\hline $\begin{array}{c}\text { Obstáculos à } \\
\text { inovação }\end{array}$ & Sintomas típicos & \multicolumn{2}{c}{ Elementos do sistema de gestão da inovação possivelmente relacionados } \\
\cline { 3 - 4 } & & Processos de inovação & Contexto organizacional para a inovação \\
\hline
\end{tabular}

- Baixa eficácia de processos

prospectivos gera falta de contexto

Dificuldade de avaliar e selecionar as melhores ideias

- Falta de confiança na robustez do processo de seleção de ideias

informacional para a avaliação e

seleção consistente de ideias

- Ausência de metodologia

estruturada para a avaliação e seleção de ideias e de uma visão compartilhada do futuro

Dificuldade para conectar os esforços empreendidos aos objetivos estratégicos

Dificuldade para transformar as boas ideias selecionadas em produtos inovadores

- Percepção de desalinhamento entre os esforços em curso e a estratégia da organização

- Gestão estratégica do portfólio de projetos inexistente ou não eficaz

- Ausência do alinhamento estratégico como critério de gestão do portfólio

- Frustração pela incapacidade de materializar ideias

- Lentidão no processo de desenvolvimento de produtos

- Processos de desenvolvimento de tecnologia e/ou produtos ausentes ou não efetivos
- Participação de membro da alta direção em fóruns ligados à estratégia de inovação como porta-voz da macroestratégia da organização

- Incapacidade de avaliar

o retorno dos esforços em

Dificuldade para medir os resultados e a performance em inovação inovação de forma estruturada

- Dificuldade de promover a inovação frente a outras iniciativas por incapacidade de justificar esforços

\section{- Desgaste e "fricção" excessiva}

Dificuldade para entre as áreas

efetuar a orquestração • Lentidão no processo de e coordenação das áreas
- Penvolvimento de produtos

- Percepção de desorganização no trabalho multifuncional
- Ausência de processos de gestão da inovação estruturados e incorporados à rotina organizacional
- Integração multifuncional pobre, dificuldade de coordenação das diversas áreas
- Ausência de indicadores para os processos de gestão da inovação
- Ausência de patrocinador na alta direção responsável por reger as iniciativas e remover as barreiras interfuncionais

- Falta de clareza nas responsabilidades das áreas nos processos de inovação

- Mecanismos de recompensa não aderentes ao trabalho coletivo e multifuncional 
organização, com entradas e saídas em suas etapas e dotada de cadência em seu conjunto.

Entretanto, o desenvolvimento dos processos de gestão da inovação também é insuficiente para que ela ocorra. Como demonstram os fundamentos teóricos apresentados, a implementação de sistemas capazes de promover a inovação de forma sistêmica exige um contexto organizacional propício para o empreendimento dos esforços de inovação. Esse contexto é traduzido pela dinâmica com que as pessoas e departamentos interagem entre si, pela configuração das instâncias de poder e dos locus de tomada de decisão, pela qualidade e abrangência dos relacionamentos da organização com o ambiente externo e pelas condições socioculturais que moldam as atitudes individuais e coletivas para a atividade inovadora.

Nesse contexto, inserido no panorama temático para o progresso da literatura ligada ao tema apresentado por Di Benedetto (2012), o presente artigo tece importante contribuição em duas dimensões. Primeiramente, estabelece um referencial teórico sistêmico potencialmente útil para pesquisas futuras, no qual elementos conceituais oriundos de diferentes campos de pesquisa são sistematizados e integrados.

Além disso, o artigo explora de forma inédita na literatura a relação conceitual entre as dimensões da gestão da inovação - contribuindo para o entendimento da interdependência entre as diversas partes do complexo sistema de inovação de uma organização - e entre os desafios à inovação enfrentados pelas organizações, seus sintomas típicos e as dimensões e práticas a eles relacionados, contribuindo assim para a compreensão das relações de causalidade e servindo de base para a construção de rotas de melhoria da performance inovativa.

\section{Referências}

ADAMS, R.; BESSANT, J.; PHELPS, R. Innovation management measurement: A review. International Journal of Management Reviews, v. 8, n. 1, p. 21-47, 2006. http:// dx.doi.org/10.1111/j.1468-2370.2006.00119.x

AMABILE, T. M. How to Kill Creativity. Harvard Business Review, v. 75, n. 5, 1998.

BAYUS, B. An analysis of product lifecycles in a technologically dynamic industry. Management Science, v. 44, n. 6, p. 763-775, 1998. http://dx.doi.org/10.1287/ mnsc.44.6.763

BONNER, J. M.; RUEKERT, R. W.; WALKER JUNIOR, O. C. Uper management control of new product development projects and project performance. Journal of Product Innovation Management, v. 19, p. 233-245, 2002. http:// dx.doi.org/10.1111/1540-5885.1930233

BRANNBACK, M. R\&D collaboration: role of Ba in knowledgecreating networks. Knowledge Management Research \&
Practice, v. 1, p. 28-38, 2003. http://dx.doi.org/10.1057/ palgrave.kmrp.8500006

BROWN, S.; EISENHARDT, K. M. Product development: past research, present findings and future directions. Academy of Management Review, v. 20, n. 2, p. 343-379, 1994.

CHESBROUGH, $\mathrm{H}$. The era of open innovation. Sloan Management Review, v. 44, n. 3, p. 35-41, 2003.

COOPER, R. G. How companies are reinventing their ideato-launch methodologies. Research Technology Management, v. 52, n. 2, p. 47-57, 2009.

COOPER, R.; EDGETT, S.; KLEINSCHMIDT, E. Portfolio management for new product development: results of an industry practices study. $R \& D$ Management, v. 31, n. 4, p. 361-380, 2001. http://dx.doi.org/10.1111/14679310.00225

Dl BENEDETTO, C. A. The JPIM thought leadership symposium. Journal of Product Innovation Management, v. 29 , n. 3, p. 344-348, 2012. http://dx.doi.org/10.1111/ j.1540-5885.2012.00904.x

DODGSON, M.; GANN, D.; SALTER, A. The role of technology in the shift towards open innovation: the case of Procter \& Gamble. R\&D Management, v. 36, n. 3, p. 333-346, 2006. http://dx.doi.org/10.1111/j.14679310.2006.00429.x

DOUGHERTY, D.; HARDY, C. Sustained product innovation in large, mature organizations: overcoming innovationto-organization problems. Academy of Management Journal, v. 39, n. 5, p. 1120-1153, 1996. http://dx.doi. org $/ 10.2307 / 256994$

GALIA, F.; LEGROS, D. Complementarities between obstacles to innovation: evidence from France. Research Policy, v. 33, p. 1185-1199, 2004. http://dx.doi.org/10.1016/j. respol.2004.06.004

HANSEN, M. T.; BIRKINSHAW, J. The innovation value-chain. Harvard Business Review, v. 85, n. 6, p. 121-130, 2007. PMid:17580654.

HARDY, C.; DOUGHERTY, D. Powering product innovation. European Management Journal, v. 15, n. 1, p. 16-27, 1997. http://dx.doi.org/10.1016/S02632373(96)00070-9

HARGADON, A.; SUTTON, R. l. Building an Innovation Factoy. Harvard Business Review, p. 158-166, 2000.

HENDERSON, R. Managing innovation in the Information Age. Harvard Business Review, v. 72, n. 1, p. 100-107, 1994.

KING, N.; ANDERSON, N. Managing innovation and change: a critical guide for organizations. London: Thomson, 2002.

LEONARD, D. Nascentes do Saber: criando e sustentando as fontes de inovação. São Paulo: Fundação Getúlio Vargas, 1998.

LEONARD, D.; SENSIPER, S. The Role of Tacit Knowledge in Group Innovation. California Management Review, v. 40, n. 3, p. 112-127, 1998. http://dx.doi. org/10.2307/41165946

NEMETH, C. Managing innovation: when less is more. California Management Review, v. 40, n. 1 , p. 59-74, 1997. http://dx.doi.org/10.2307/41165922

NONAKA, 1.; TAKEUCHI, H. Criação de conhecimento na empresa. Rio de Janeiro: Campus, 1997.

ORGANIZAÇÃO PARA A COOPERAÇÃO E DESENVOLVIMENTO ECONÓMICO - OCDE. Manual de Oslo - diretrizes para 
coleta e interpretação de dados sobre inovação. Brasília: FINEP, 2006.

PARTHASARTHY, R.; HAMMOND, J. Product innovation input and outcome: moderating effects of the innovation process. Journal of Engineering and Technology Management, v. 19, p. 75-91, 2002. http://dx.doi. org/10.1016/S0923-4748(01)00047-9

PEREZ-FREIJE, J.; ENKEL, E. Creative tension in the innovation process: how to support the right capabilities. European Management Journal, v. 15, n. 1, p. 11-24, 2007. http:// dx.doi.org/10.1016/j.emj.2006.11.005

PHAAL, R.; FARRUKH, C. J. P.; PROBERT, D. Technology roadmapping: A planning framework for evolution and revolution. Technological Forecasting \& Social Change, v. 71, p. 5-26, 2004. http://dx.doi.org/10.1016/S00401625(03)00072-6

POWELL, W. W. Learning from collaboration: knowledge and networks in the biotechnology and pharmaceutical industries. California Management Review, v. 40, n. 3, p. 228-240, 1998. http://dx.doi.org/10.2307/41165952

QUADROS, R. Aprendendo a inovar. padrões de gestão da inovação tecnológica em empresas industriais brasileiras. Campinas: Universidade Estadual de Campinas, 2008. Relatório de pesquisa "Padrões de gestão da inovação tecnológica em empresas brasileiras”, apresentado ao CNPq.

ROTHWELL, R. Successful industrial innovation: critical success factors for the 1990s'. $R \& D$ Management, v. 22, n. 3, p. 221 239, 1992. http://dx.doi.org/10.1111/j.1467-9310.1992. tb00812.x

SALAMAN, G.; STOREY, J. Managers' Theories about the Innovation Process. Journal of Management Studies, v. 39, n. 2, p. 147-165, 2002. http://dx.doi.org/10.1111/14676486.00286
SLOCUM, M. S.; LUNDBERG, C. 0. Technology Forecasting: From Emotional to Empirical. Creativity and Innovation Management, v. 10, n. 2, p. 139-152, 2003. http:// dx.doi.org/10.1111/1467-8691.00215

SHARMA, A. Central dilemmas of managing innovation in large firms. California Management Review, v. 3941, n. 3, p. 146-164, 1999. http://dx.doi.org/10.2307/41166001

SHELL. People and connections: Global Scenarios to 2020. Shell International Ltd, 2002.

SHIRAHADA, K.; NIWA, K. Future-oriented mindset's contribution to management of corporate R\&D personnel motivation in Japan. Journal of Innovation and Technology Management, v. 4, n. 4, p. 375-392, 2007. http://dx.doi.org/10.1142/S0219877007001144

SIEMENS. Pictures of the future. Siemens: The Magazine for Research and Innovation, Siemens AG Publications, 2008.

STRINGER, R. How to manage radical innovation. California Management Review, v. 42, n. 4, p. 70-88, 2000. http:// dx.doi.org/10.2307/41166054

THAMHAIN, H.J. Managing innovative R\&D teams. $R \& D$ Management, v. 33, n. 3, p. 297-311, 2003. http://dx.doi. org/10.1111/1467-9310.00299

TIDD, J.; BESSANT, J.; PAVITT, K. Gestão da inovação. 3ed. São Paulo: Artmed, 2008.

TUSHMAN, M.; ANDERSON, P. Managing Strategic Innovation and Change. Oxford: Oxford University Press, 1997. p. 3-23.

VON HIPPEL, E. Democritizing Innovation. Cambridge: The MIT Press, 2005.

WHEELWRIGHT, S. C.; CLARK, K. B. Revolutionizing product development process: quantum leaps in speed, efficiency, and quality. New York: The Free Press, 1992.

\section{Product innovation management: an integrated model proposal}

\section{Abstract}

The aim of this paper is to provide a theoretical overview of the product innovation management process and its challenges. Despite wide recognition of the importance of innovation, there is a consensus that management practices that maximize innovation are still not fully understood. Various authors have demonstrated the complexity of the innovation process by showing that it involves a detailed combination of risk and uncertainty and the need for intense multifunctional orchestration to attempt to strike a balance between creation and discipline. Despite advances over the last decade, the literature still lacks studies that bring together contributions from different fields of knowledge into integrated models for systemic management innovation. Based on current bibliography reviews, a model that includes three aspects (process, context and resources) is proposed, and the challenges of innovation are investigated from the perspective of structuration theory. This paper provides a conceptual synthesis and a theoretical framework that can be useful for future research on this topic.

\section{Keywords}

Innovation. Management. Product. Process. Organization. Model. 